\title{
Mustela putorius furo
}

National Cancer Institute

\section{Source}

National Cancer Institute. Mustela putorius furo. NCI Thesaurus. Code C161001.

The common domestic ferret, Mustela putorious furo. 